\title{
SCAVENGING ACTIVITY OF DICLOFENAC. INTERACTION WITH ABTS RADICAL CATION AND PEROXYL RADICALS
}

\author{
C. ROJO, M. J. ÁLVAREZ-FIGUEROA, ${ }^{1} M$. SOTO,$^{2}$ A. CAÑETE, ${ }^{3}$ \\ D. PESSOA-MAHANA, ${ }^{1}$ C. LÓPEZ-ALARCÓN ${ }^{1 *}$ \\ ${ }^{1}$ Departamento de Farmacia, Facultad de Química, Pontificia Universidad Católica de Chile. C.P. 782 0436, Santiago, Chile. \\ ${ }^{2}$ Departamento de Química Física, Facultad de Química, Pontificia Universidad Católica de Chile. \\ ${ }^{3}$ Departamento de Química Orgánica, Facultad de Química, Pontificia Universidad Católica de Chile, Santiago, Chile. \\ (Received 25 April 2008 - Accepted 22 July 2008)
}

\begin{abstract}
The scavenging activity of diclofenac was estimated by its capability to bleach ABTS radical cation, and ORAC (oxygen radical absorbance capacity) methodology. In addition, GC-MS technique was used to establish if the lactamic derivative of diclofenac was formed as final product in the interaction with peroxyl radicals. Diclofenac bleached ABTS radical cation in a concentration-dependent way. In ORAC assays, diclofenac inhibited the consumption of fluorescein and c-phycocyanin mediated by peroxyl radicals. An ORAC-fluorescein, and ORAC-c-phycocyanin value of 0.3 , and 0.004 was estimated, respectively. From the downcurvature observed in Stern-Volmer-like plots, we postulated that the low protection of c-phycocyanin is related to secondary damage of c-phycocyanin by the secondary radical of diclofenac. By GC-MS studies only a 2,6-dichloroaniline derivative was detected as product after the reaction with peroxyl radicals.
\end{abstract}

Key Words: Diclofenac, fluorescein, c-phycocyanin, ORAC, scavenging activity.

\section{INTRODUCTION}

Diclofenac (2-[(2,6-dichlorophenyl)amino]benzenacetic acid) is a synthetic non steroidal anti-inflammatory drug, widely employed in the treatment of different pathologies associated to inflammation processes, such as chronic arthritis, rheumatoid arthritis, osteoarthritis, and ankylosing spondylitis. ${ }^{1,2}$ The mechanism of action is related to the inhibition of the arachinodate metabolites synthesis through cyclooxygenase inhibition. ${ }^{1,2}$

Besides of the well known anti-inflammatory effect of diclofenac, some scavenging properties have been also reported for this drug. The inhibition of both, phosphatidylcholine liposomes oxidation ${ }^{3}$ and linoleic acid peroxidation has been informed. ${ }^{4}$ In addition, a reduction in the chemiluminescence associated with phosphatidylcholine hydroperoxide production in rats plasma subjected to ischemia-reperfusion process was reported. ${ }^{5}$ Furthermore, YouZhi et al. ${ }^{6}$ have reported that diclofenac protects human erythrocytes against hemolysis process induced by peroxyl radicals. All these reports suggest -at least in vitro- some scavenging activity of diclofenac, which could effectively provide protection against lipid peroxidation caused either by hydroxyl radicals, ${ }^{3} \mathrm{Fe}^{2+} /$ ascorbate system, ${ }^{4}$ ischemia-reperfusion ${ }^{5}$ or peroxyl radicals damage ${ }^{6}$ Nevertheless, diclofenac was not able to protect LDL (low density lipoproteins) against oxidation induced by copper. ${ }^{7}$

In spite of that some studies have suggested scavenging activity of diclofenac, ${ }^{3-6}$ there is only a few studies reporting the diclofenac-free radicals interactions. Gaudiano et al. ${ }^{8}$ suggested the formation of hydroxylated metabolites as oxidation/degradation products of diclofenac in presence of hydroxyl radical. Recently, Fodor et al. ${ }^{9}$ reported that the protection of crocin afforded by diclofenac was similar to acetaminophen, but considerably lower than 3,4-dihydroxybenzoic acid. ${ }^{9}$

To the best of our knowledge, studies on the scavenging activity of diclofenac using a stable free radical or using an ORAC methodology have not been developed. Then, the aim of this study was to investigate the antioxidant capacity of diclofenac using both, a stable free radical as ABTS radical cation $\left(\mathrm{ABTS} \ddot{Y}^{+}\right.$), and the ORAC methodology. In ORAC assays, fluorescein and c-phycocyanin were used as target molecules. In addition, GC-MS studies were performed in order to establish if the lactamic derivative of diclofenac is generated during the reaction with peroxyl radicals.

\section{EXPERIMENTAL}

Chemicals

2,2'-azo-bis(2-amidinopropane) dihydrochloride (AAPH), 2,2'-azinobis(3-ethylbenzthiazoline-6-sulfonic acid) diammonium salt (ABTS), fluorescein, Trolox -a water soluble vitamin E analog used as reference antioxidant- (see Figure 1), c-phycocyanin (c-Pc), and manganese dioxide $\left(\mathrm{MnO}_{2}\right)$ were purchased by Sigma-Aldrich (St. Louis, MO, USA). Diclofenac sodium salt (Figure 1) was purchased by Instituto Sanitas laboratory (Chile). All compounds were employed as received. The c-Pc concentration was estimated by considering a Mw of ca. 13,000 per each bilin group.<smiles>O=C(O)c1ccccc1-c1c2ccc(=O)cc-2oc2cc(O)ccc12</smiles>

Fluorescein<smiles>Cc1c(C)c2c(c(C)c1O)CC(C)(C(=O)O)CO2</smiles>

Trolox<smiles></smiles>

AAPH<smiles>[NH3+]C(=O)Cc1ccccc1Nc1c(Cl)cccc1Cl</smiles>

Diclofenac sodium salt<smiles></smiles>

ABTS
Figure 1: Chemical structure of diclofenac sodium salt, AAPH, Trolox, ABTS, and fluorescein.

Interaction of diclofenac with ABTS radical cation (ABTS $\left.\ddot{Y}^{+}\right)$

$\mathrm{ABTS}^{+}$was generated from ABTS oxidation by manganese dioxide activated solid $\left(\mathrm{MnO}_{2}\right) \cdot{ }^{10}$ Oxidation of ABTS $(150 \mu \mathrm{M})$ in phosphate buffer (75 $\mathrm{mM}$ at $\mathrm{pH}$ 7.4) was carried out at room temperature employing an excess of $\mathrm{MnO}_{2}$, which was removed by centrifugation and filtration. The resulting blue-green solution of ABTSŸ ${ }^{+}$was kept at $4^{\circ} \mathrm{C}$ before its use. The ABTS $\ddot{Y}^{+}$ concentration was derived from its absorbance at $734 \mathrm{~nm}\left(\varepsilon_{734}=0.015 \mu \mathrm{M}^{-1}\right.$ $\left.\mathrm{cm}^{-1}\right) .^{11}$ The absorbance of ABTSŸ ${ }^{+}$remained constant for several hours. The reaction was started by adding diclofenac to the ABTS $\ddot{Y}^{+}$solution, and the reaction was followed by measuring the decay in absorbance at $734 \mathrm{~nm}$. Measurements were recorded in a thermostatized cuvette of an Agilent 8453 (Palo Alto, CA, USA) UV-visible spectrophotometer. The reaction was carried out at room temperature in air saturated solutions. In addition, the decrease in the 
absorption units of $\mathrm{ABTSY}^{+}$at $734 \mathrm{~nm}$ after 6 min of the addition of diclofenac or Trolox was used to calculate TEAC (Trolox equivalent antioxidant capacity) value (Eqn 1). ${ }^{12}$

$$
T E A C=\frac{\left[\Delta U A_{\text {dlche ıac }}\right]}{\left[\Delta \mathrm{AA}_{\text {Trobx }}\right]} \times \frac{[\text { Trolox }]}{[\text { Diclofenac }]}
$$

Where:

$\Delta \mathrm{UA}_{\text {diclofenac }}=$ Difference between initial absorbance $\left(\mathrm{UA}_{0 \text { minutes }}\right)$ and after 6 minutes of diclofenac addition (UA

$\Delta \mathrm{UA}_{\text {Trolox }}=$ Difference between initial absorbance $\left(\mathrm{UA}_{0 \text { minutes }}\right)$ and after 6 minutes of Trolox addition $\left(\mathrm{UA}_{6 \text { minutes }}\right)$

$[$ Trolox $]=$ Trolox molar concentration

$[$ Diclofenac $]=$ Diclofenac molar concentration .

\section{Protection of c-phycocyanin, and fluorescein}

Stock solutions of diclofenac $(1 \mathrm{mM})$, and Trolox $\left(1 \times 10^{-2} \mathrm{M}\right)$ were prepared daily in ethanol immediately before their use. Stock solutions of AAPH (0.6 $\mathrm{M})$, fluorescein $\left(1 \times 10^{-5} \mathrm{M}\right)$, and c-Pc $(80 \mu \mathrm{M})$ were prepared daily in phosphate buffer $(75 \mathrm{mM}, \mathrm{pH} 7.4)$. A reaction mixture containing AAPH $(10 \mathrm{mM})$, the target molecule (fluorescein, $70 \mathrm{nM}$, or c-Pc, $0.8 \mu \mathrm{M}$ ) with or without diclofenac or Trolox was incubated in phosphate buffer $(75 \mathrm{mM})$ at $\mathrm{pH} 7.4$, at $37^{\circ} \mathrm{C}$ in the thermostatized cuvette of a Perkin Elmer LS-55 spectrofluorimeter (Beaconstield, U.K). The consumption of fluorescein, and c-Pc were evaluated from the decrease in its fluorescence intensity. In fluorescein protection assays, $493 \mathrm{~nm}$ and $515 \mathrm{~nm}$ were used as excitation and emission wavelengths, respectively, meanwhile $620 \mathrm{~nm}$ and $640 \mathrm{~nm}$ were the respective wavelengths in c-Pc experiments.

\section{ORAC determinations}

ORAC experiments were carried out according to Ou et al. procedure. ${ }^{13}$ Fluorescein and c-Pc consumption were evaluated from the progressive decrease in the sample fluorescence intensity $(\mathrm{F})$. Values of $\left(\mathrm{F} / \mathrm{F}_{0}\right)$ were plotted as a function of time. Integration of the area under the curve (AUC) was performed up to a time such that $\left(\mathrm{F} / \mathrm{F}_{0}\right)$ reached a value of 0.2 . These areas were employed to obtain ORAC values (Eqn. 2). All experiments were carried out in triplicate.

$$
\mathrm{ORAC}=\frac{\left[\mathrm{AUC}-\mathrm{AUC}^{0}\right]}{\left[\mathrm{AUC}_{\mathrm{TDbx}}-\mathrm{AUC}^{0}\right]} \times \frac{[\text { Trolox }]}{[\text { DiclofenaC }]}
$$

Where:

$\mathrm{AUC}=$ Area under curve in presence of diclofenac, integrated between time zero and that corresponding to $80 \%$ of the probe consumption.

$\mathrm{AUC}^{\mathrm{o}}=$ Area under curve for the control (in absence of diclofenac).

$\mathrm{AUC}_{\text {Trolox }}=$ Area under curve for Trolox.

$[$ Trolox $]=$ Trolox molar concentration.

$[$ Diclofenac $]=$ Diclofenac molar concentration .

\section{GC-MS studies}

Solutions of diclofenac $(20 \mu \mathrm{M})$ plus AAPH $(10 \mathrm{mM})$, in phosphate buffer $(\mathrm{pH} 7.4,75 \mathrm{mM})$, before and after 3 hours incubation at $37^{\circ} \mathrm{C}$, were analyzed by GC-MS. Previously to the chromatographic analysis, the solutions were extracted with ethyl acetate. Briefly, $1 \mathrm{~mL}$ of ethyl acetate was added to an equal volume of each sample, and the organic phase was filtered and injected immediately to the chromatograph. GC-MS analysis was performed with a Thermo Electron Corporation Trace GC Ultra double-focusing sector instrument (MAT 95 XP Thermo Electron Bremen, Germany). The GC Ultra with autosampler AS 3000, was equipped with a MDN-5S ms. capillary column $(30 \mathrm{~m}, 0.25 \mathrm{~mm}$ ID, $0.25 \mu \mathrm{m}$ film; SUPELCO 595, North Harrison Road, Bellefonte, USA). Chromatographic conditions: Source temperature, $260{ }^{\circ} \mathrm{C}$; Injector temperature, $260{ }^{\circ} \mathrm{C}$; splitless $/ \mathrm{w}$ Surge, split Flow $12 \mathrm{ml} / \mathrm{min}$, splitless time $1.50 \mathrm{~min}$, surge pressure $45 \mathrm{psi}$; surge duration $1.50 \mathrm{~min}$.

Temperature program: The oven temperature was programmed from $50(1$ min), to $180{ }^{\circ} \mathrm{C}$ (hold for $7 \mathrm{~min}$ ) at $10{ }^{\circ} \mathrm{C} \mathrm{min}-1$, to $250^{\circ} \mathrm{C}$ (hold for $5 \mathrm{~min}$ ) at $10^{\circ} \mathrm{C}$ min-1; run time was 33 minutes. Helium was used as carrier gas with an inlet pressure of $14.5 \mathrm{psi}$. The identification of the samples was based on the analyses of the mass spectra (full scan). Quantification of the GC-MS peaks was carried out using lidocaine as internal standard.

\section{RESULTS AND DISCUSSION}

Interaction of diclofenac with ABTS radical cation (ABTS ${ }^{\square+}$ )

The reaction of antioxidants with stable free radicals has been widely employed as an estimation of their free radical scavenging capacities. ABTS ${ }^{++}$ has been frequently employed for these purposes, mainly due to their solubility in buffer solutions. ${ }^{14}$ When different diclofenac concentrations were added to an $\mathrm{ABTS}^{\square+}$ solution, a decrease of the absorbance at $734 \mathrm{~nm}$ (corresponding to $\mathrm{ABTS}^{\square+}$ ) was observed (Figure 2). From a bi-exponential adjust of the data presented in Figure 2, a stoichiometric factor (n, defined as the number of $\mathrm{ABTS}^{\square+}$ consumed per each molecule of diclofenac) of $2.0 \pm 0.5$ was estimated. In addition, the initial rate of ABTS ${ }^{\square+}$ bleaching was dependent of the diclofenac concentration (Figure 2). For example, at diclofenac $5 \mu \mathrm{M}$ an initial rate of $3.1 \mu \mathrm{M} / \mathrm{min}$ was estimated, while at diclofenac $20 \mu \mathrm{M}$, the initial rate was $20 \mu \mathrm{M} / \mathrm{min}$. These values show that diclofenac efficiently bleached $\mathrm{ABTS}^{\square+}$. In fact, nearly $80 \%$ of $\mathrm{ABTS}^{\square+}$ (initial concentration, $30 \mu \mathrm{M}$ ) was bleached after $6 \mathrm{~min}$ incubation with $20 \mu \mathrm{M}$ diclofenac, leading to a TEAC (Trolox equivalent antioxidant capacity) value of 1.4. Nevertheless, it is important to considerer that kinetic profiles of the ABTS ${ }^{\square+}$ bleaching induced by Trolox and diclofenac were different each other. While diclofenac reacted with ABTS ${ }^{\square}$ giving the kinetic profiles of Figure 2, Trolox bleached ABTS instantaneously.

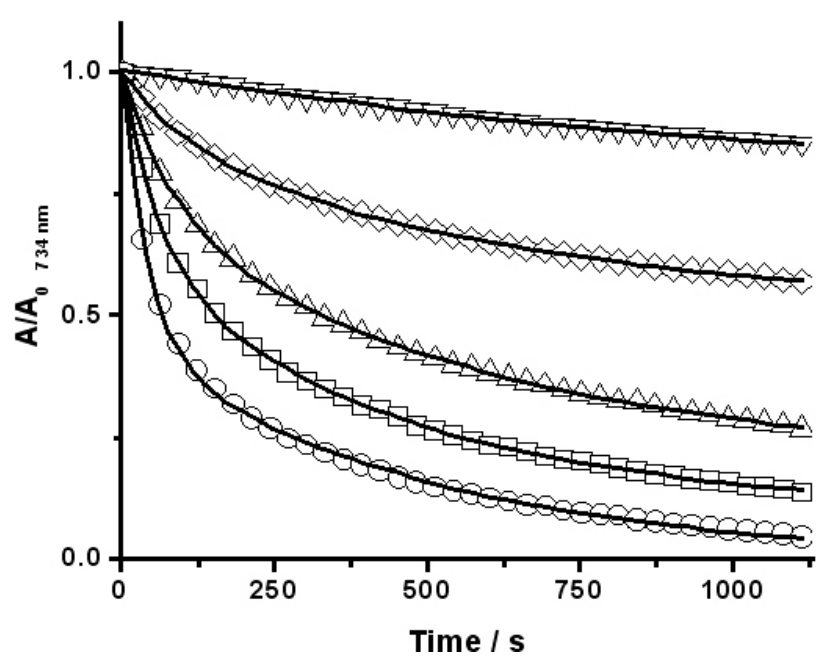

Figure 2: Kinetics profiles of ABTS radical cation $\left(\mathrm{ABTS}^{+}\right)$bleaching by diclofenac. $\mathrm{ABTSY}^{+}(30 \mu \mathrm{M})$ was incubated in phosphate buffer $(75 \mathrm{mM}, \mathrm{pH}$ 7.4) in presence of different diclofenac concentrations. Control (S); diclofenac: $5 \mu \mathrm{M}\left({ }^{-}\right), 10 \mu \mathrm{M}(\mathrm{r}), 15 \mu \mathrm{M}(\mathfrak{f})$, and $20 \mu \mathrm{M}\left({ }^{\mathrm{TM}}\right)$. ABTSYY $\ddot{Y}^{+}$consumption was monitored through the decrease in ABTS ${ }^{+}$absorption intensity at $734 \mathrm{~nm}$.

\section{Protection of target molecules by diclofenac}

Protection of fluorescein (ORAC-fluorescein)

The ORAC index has been widely employed in the antioxidant capacity evaluation of single antioxidants and their complex mixtures. ${ }^{13}$ This methodology measures the protection afforded by an antioxidant to a target molecule that is being oxidized by peroxyl radicals, estimating the changes of area under curve of the kinetics profiles for the target molecule decay in fluorescence or absorbance. ORAC assay was proposed originally by Cao et al. ${ }^{15}$ using phycoerythrin as target molecule, but at present, fluorescein is the target molecule most employed. ${ }^{13}$ In order to evaluate the antioxidant capacity of diclofenac, protective experiments using fluorescein as target molecule were carried out. As can be seen in Figure 3, a reduced consumption rate of fluorescein was observed when diclofenac was added to a solution containing fluorescein plus AAPH. The protection of fluorescein afforded by diclofenac, would be related with the reaction between diclofenac and peroxyl radicals, and can be explained by the follow set of reactions: 


$$
\begin{aligned}
& \mathrm{AAPH}+\mathrm{O}_{2} \longrightarrow 2 \mathrm{ROO}^{\circ}+\mathrm{N}_{2} \\
& \mathrm{ROO}^{\circ}+\text { fluorescein } \longrightarrow \text { bleaching }
\end{aligned}
$$

$\mathrm{ROO}^{\bullet}+$ diclofenac $\longrightarrow$ diclofenac $^{\bullet}+\mathrm{ROOH}$

$$
2 \mathrm{ROO} \cdot \longrightarrow \text { non radicals products }
$$

For simplicity, we do not consider the formation of alkoxyl radicals in reaction (6), and the self-reactions of the radicals produced in step (5).

Figure 3 shows that diclofenac protects fluorescein without generating an induction time. Considering that the protection of fluorescein by antioxidants usually is through a lag time (induction time), even for antioxidants of low reactivity, ${ }^{16}$ the data presented in figure 3 , indicate that diclofenac would have a very low reactivity towards peroxyl radicals. However, when the area under curve (AUC) estimated from the kinetic profiles of Figure 3 were compared with Trolox (Figure 3, insert), the ORAC-fluorescein index of diclofenac (Eqn. (2)) was nearly three times lower than Trolox (ORAC-fluorescein $\approx 0.3$ ). Interestingly, the antioxidant capacity estimated from AUC (ORAC) contrasts with the evaluation of initial rates of fluorescein fluorescence decay. Thus, while diclofenac protected fluorescein without induction time (Figure 3), Trolox inhibited fluorescein consumption through a neat lag time. ${ }^{16}$ Therefore, the antioxidant capacity of diclofenac strongly depends on the criteria of analysis of figure 3 data. If only AUC is considerer to estimate the antioxidant capacity, diclofenac seems with a comparable scavenging capacity that Trolox. Nevertheless, if is considered the initial consumption rate as an antioxidant capacity parameter, diclofenac appears to have a very lower reactivity than Trolox.

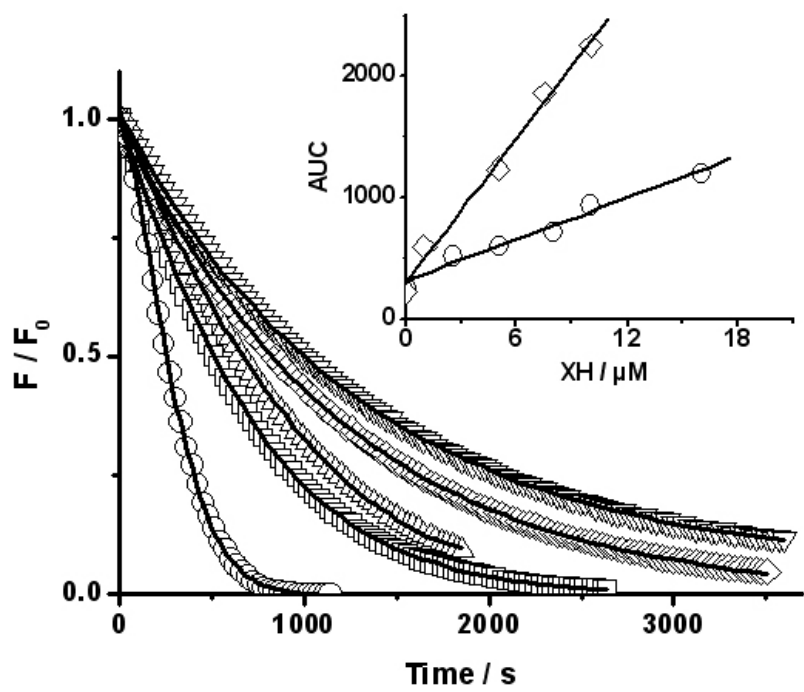

Figure 3: Kinetic profiles of fluorescein consumption AAPH mediated in presence of diclofenac. Fluorescein $(70 \mathrm{nM})$ was incubated in presence of AAPH $(10 \mathrm{mM})$ with or without diclofenac in phosphate buffer $(75 \mathrm{mM}$, $\mathrm{pH} 7.4)$ at $37^{\circ} \mathrm{C}$. The reaction was followed by the decrease in fluorescein fluorescence intensity (excitation at $493 \mathrm{~nm}$, emission at $515 \mathrm{~nm}$ ). Control ( ${ }^{\mathrm{TM}}$ ); diclofenac: $5 \mu \mathrm{M}(\square), 8 \mu \mathrm{M}(\mathrm{r}), 10 \mu \mathrm{M}\left({ }^{(}\right)$, and $16 \mu \mathrm{M}$ (S). Insert: dependence of the area under curve after $80 \%$ of reaction versus diclofenac $\left({ }^{\mathrm{TM}}\right)$ or Trolox $(-)$ concentration $(\mu \mathrm{M})$. Trolox data were taken from ref. 16.

Protection of c-Phycocyanin (ORAC-c-Pc)

The bleaching rate of c-Pc by peroxyl radicals can be modified by the presence of compounds able to react with the primary radicals. Phycobiliproteins, such as c-Pc and phycoerythrine, ${ }^{17}$ have been employed in order to evaluate the free radical scavenging capacity of several compounds. The presence of additives modifies the AUC of the kinetic profiles of c-Pc consumption (ORAC type methodologies), and the initial rate of $\mathrm{c}-\mathrm{Pc}$ bleaching. We have employed both approaches to estimate the protective capacity of diclofenac. Figure 4 shows the effect of diclofenac on c-Pc bleaching promoted by AAPH. From the AUC of the kinetics profiles $\left(\mathrm{F} / \mathrm{F}_{0}\right)$ of $\mathrm{c}-\mathrm{Pc}$ bleaching shown in Figure 4, an ORAC-c-Pc value nearly to 0.004 was estimated. This value was 75 times lower than the ORAC-fluorescein index, and shows that ORAC values are extremely dependent upon the employed target molecule. ${ }^{18}$

As can be seen in figure 4, the addition of high diclofenac concentrations $(50-500 \mu \mathrm{M})$ generated a decrease in the bleaching rate of c-Pc. This behaviour would be related with a low efficiency of diclofenac, and could be represented by reactions (3), (5), (6), and (7): ${ }^{17}$

$$
\mathrm{ROO}+\mathrm{C}-\mathrm{PC} \longrightarrow \text { bleaching }
$$

The dependence of $\mathrm{R}^{\circ} / \mathrm{R}$ ratio (where $\mathrm{R}^{\circ}$ is the initial rate of c-Pc bleaching in absence of diclofenac, and $\mathrm{R}$ the initial rate of the process in presence of diclofenac) with diclofenac concentration was studied (Stern-Volmer like plots). As is shown in the insert of figure 4, a clear downcurvature was observed in this plot. This result can not be explained in terms of the simple mechanism depicted by reactions (3), (5), (6), and (7), and could be related to secondary reactions of diclofenac derived radicals (diclofenac $\ddot{Y}$ ), such as: ${ }^{19,20 "}$

$$
\text { Diclofenac }{ }^{*} \mathrm{C}-\mathrm{PC} \rightarrow \text { bleaching }
$$

The maximum attainable $\mathrm{R}^{\circ} / \mathrm{R}$ value $\left(\mathrm{R}^{\circ} / \mathrm{R}_{\infty}\right.$ values) can be considered as an indicator of the damaging capacity of the diclofenac' radical. The $\mathrm{R}^{\circ} / \mathrm{R}$ value of diclofenac (estimated in the plateau of Figure 4, insert) was nearly 2.0. This value implies that diclofenac have a secondary damage higher than phenols such as protocatechuic acid, kaempferol, and luteolin. ${ }^{19}$ However, the secondary damage of diclofenac was similar to galangin. ${ }^{19}$ This would be compatible with the suggestion that compounds with lower reactivity towards AAPH derived peroxyl radicals would have higher secondary damage. ${ }^{19}$ Interestingly, in the protection of fluorescein by diclofenac a linear relationship $\left(\mathrm{R}^{0} / \mathrm{R}=1.042+\right.$ $0.079, r=0.9944$ ) was observed in the $R^{0} / R$ versus diclofenac concentration plots (data not shown), indicating that in this system the secondary radical of diclofenac would not be able to damage fluorescein.

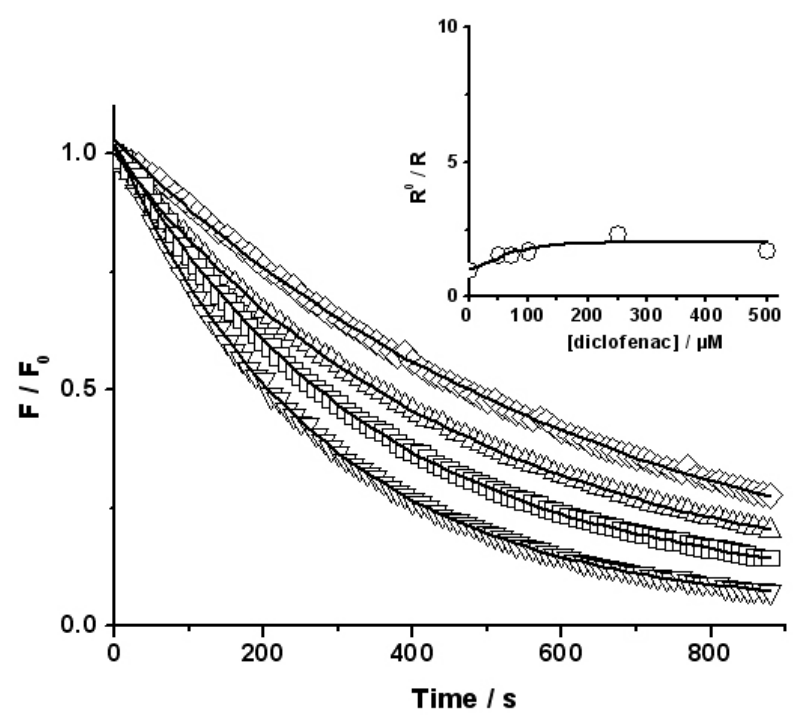

Figure 4: Bleaching of c-Phycocyanin elicited by AAPH $(10 \mathrm{mM})$ in presence of diclofenac. c-Pc $(0.8 \mu \mathrm{M})$ was incubated in presence of AAPH $(10$ $\mathrm{mM}$ ) with or without diclofenac. Control (S). Diclofenac: $50 \mu \mathrm{M}(\square) ; 250 \mu \mathrm{M}$ (r); $500 \mu \mathrm{M} \mathrm{(-)}$.The reaction was followed by the decrease in c-Pc fluorescence intensity (excitation at $620 \mathrm{~nm}$, emission at $640 \mathrm{~nm}$ ) at $37^{\circ} \mathrm{C}$. Insert: dependence of $\mathrm{R}^{0} / \mathrm{R}$ ratio with diclofenac concentration. $\mathrm{R}^{0}$, and $\mathrm{R}$ represent the initial rate of c-Pc consumption in absence, and presence of diclofenac, respectively.

GC-MS studies 
In spite of the low efficiency of diclofenac as scavenging compound, the results above shown are a clear evidence that diclofenac reacted with peroxyl radicals, and could explain previous reports that show some antioxidant effect of diclofenac. ${ }^{3-6}$ You-Zhi et al. ${ }^{6}$ reported that diclofenac inhibited human erythrocytes hemolysis mediated by peroxyl radicals AAPH derived. The authors described the effect of diclofenac through a diclofenac-peroxyl radicals interaction with the formation of a lactamic form of diclofenac (1- $(2,6-$ dichlorophenyl)indolin-2-one) as final product. In order to determine if in our experimental conditions the lactamic product is formed, we used GC-MS technique. For this purpose, direct extraction of a diclofenac-AAPH solution (before and after incubation at $37^{\circ} \mathrm{C}$ ) was carried out, and the organic phase was injected in to the chromatograph. No acidification of the solutions was used for minimizing the formation of 1-(2,6-dichlorophenyl)indolin-2-one as catalytic product. ${ }^{21}$ Figure 5, and Figure 6 show the GC-MS chromatogram and the fragmentation pattern of a diclofenac-AAPH solution at zero time, and after three hours incubation at $37^{\circ} \mathrm{C}$, respectively. As can be seen in Figure $\mathbf{5 A}$, at zero time only a peak at 26.6 minutes was registered. The fragmentation pattern of this peak (Figure 5B), with a base peak $(\mathrm{Bp})=214, \mathrm{~m} / \mathrm{z}(1)=$ 242 , and an ion molecular $\left(\mathrm{M}^{+}\right)=277$, corresponds to the lactamic form of diclofenac. ${ }^{21}$ This result indicates that a fraction of lactame can be formed from diclofenac before the reaction with peroxyl radicals. This agree with reports describing the lactame as a synthesis intermediate of diclofenac (impurity A of the British pharmacopoeia). ${ }^{22,23}$ As can be seen in Figure 6, after three hours incubation with AAPH, two peaks were registered. The peak at 26.6 minutes, corresponding to the lactamic form, had a similar area under curve compared with zero time (data not shown), leading that the lactamic derivative was not formed during the reaction. The second one at 10 minutes, had a pattern fragmentation according to 2,6-dichloroaniline (Figure 6B). This result implies that a fragmentation of diclofenac during the reaction with AAPH derived radicals is involved.

Figure 5: Extracted ion chromatogram (graphic A) and mass spectrum
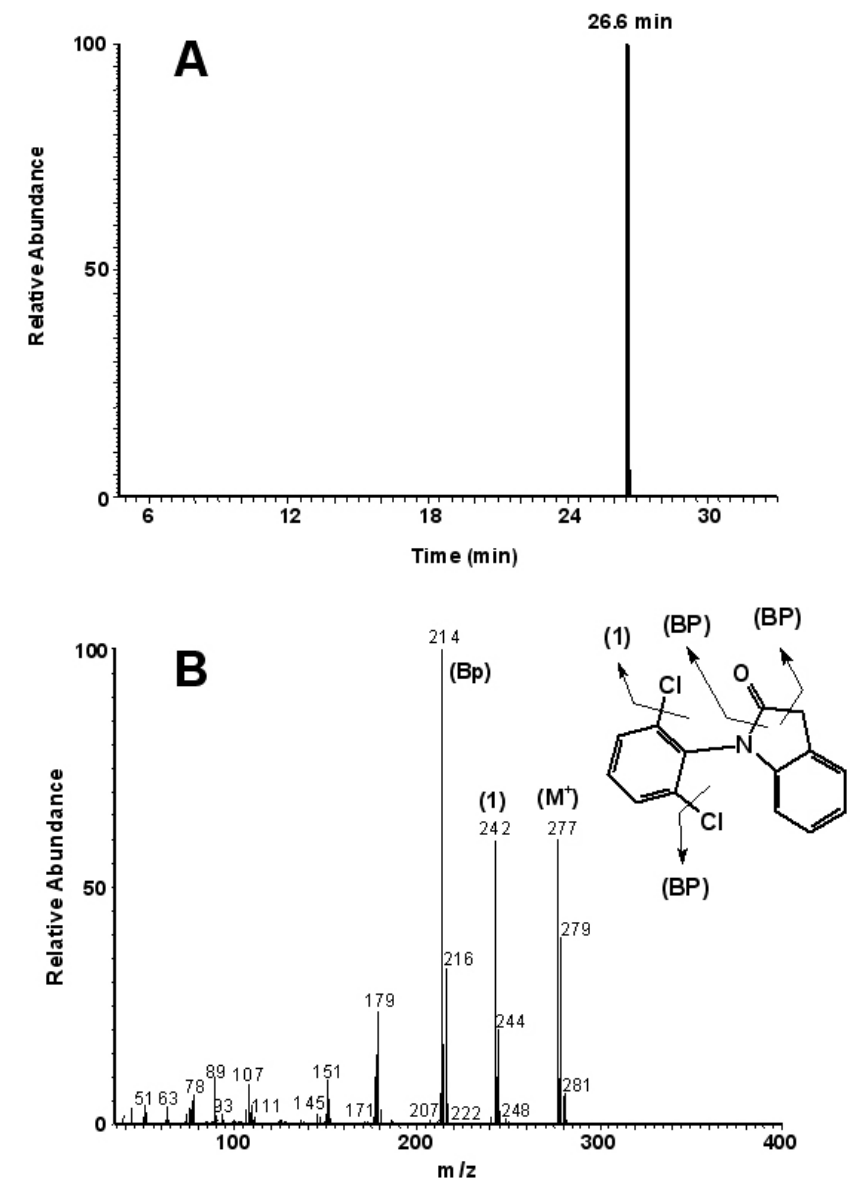

(graphic B) of a solution containing diclofenac $(20 \mu \mathrm{M})$ plus AAPH $(10 \mathrm{mM})$ at zero reaction time in phosphate buffer $75 \mathrm{mM}, \mathrm{pH} 7.4$.

Figure 6: Extracted ion chromatogram (graphic A) and mass spectrum
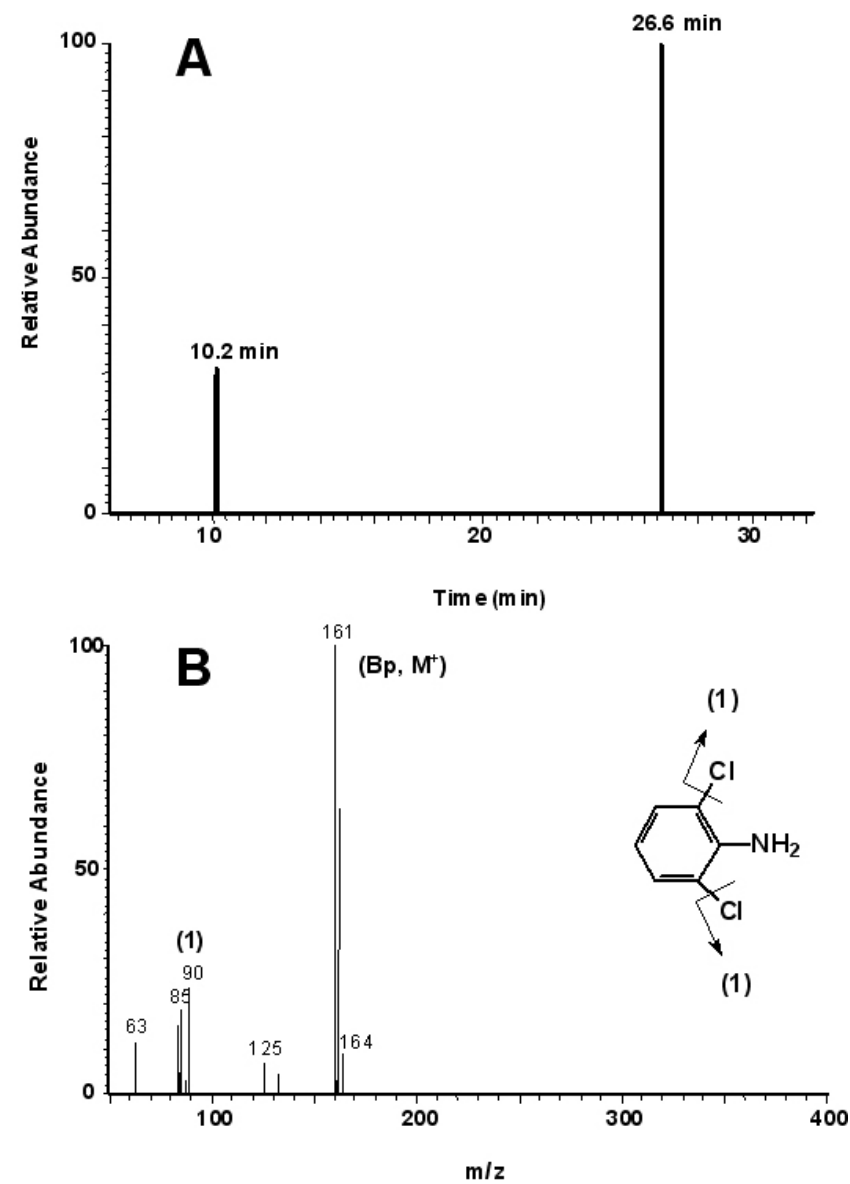

(graphic B) of a solution containing diclofenac $(20 \mu \mathrm{M})$ plus AAPH $(10 \mathrm{mM})$ after 3 hours incubation at $37^{\circ} \mathrm{C}$ in phosphate buffer $75 \mathrm{mM}, \mathrm{pH}$ 7.4. Graphic $\mathrm{B}$ represents the fragmentation pattern of the chromatographic peak at 10.2 minutes.

\section{CONCLUSIONS}

All data obtained in the present work indicate that diclofenac is able to react with a stable free radical (ABTS radical cation), and peroxyl radicals. The scavenging capacity of diclofenac estimated by ORAC-like methodologies lead that diclofenac is a mild peroxyl radical scavenger. However, its ability for trapping peroxyl radicals should be considered in topical administration of pharmaceutical preparations containing high diclofenac concentrations.

\section{ACKNOWLEDGMENTS}

This work was supported by FONDECYT ( $\left.{ }^{\circ} 11060323\right)$

\section{REFERENCES}

1. D. Williams, T. Lemke, "Foye's Principles of Medicinal Chemistry," $5^{\text {th }}$ ed., Lippincott Williams and Wilkins, Philadelphia, 2002.

2. J. A. Mitchell, T. D. Warner, Br. J. Pharmacol., 128, 1121, (1999).

3. F. Maffei, M. Carini, G. Aldini, L. Saibene, A. Macciocchi, Int. J. Tissue React., 15, 225, (1993).

4. A. Mouithys-Mickalad, S-X. Zheng, G. Deby-dupont, C. Deby, M. Lamy, J. Reginster, Y. Henrotin, Free Radic. Res., 33, 607, (2000).

5. F. Takayama, T. Egashira, Y. Yamanaka, Jpn. J. Pharmacol., 64, 71, (1994).

6. T. You-Zhi, L. Zai-Qun, J. Pharm. Pharmacol., 58, 625, (2006).

7. M. Walter, R. Jacob, Ch. A. Daya, R. Dahlborga, Y. Wenga, R. P. Mason, Atherosclerosis, 177, 235, (2004).

8. M. Gaudiano, L. Valvo, P. Bertocchi, L. Manna, J. Pharm. Biomed. Anal., 32, 151, (2003).

9. K. Fodor, A. Léhman, P. Perjési, Acta Pharm. Hung., 76, 140, (2006). 
10. C. Henriquez, C. Aliaga, E. Lissi, Int. J. Chem. Kinet., 34, 659, (2002).

11. S. Scott, W. Chen, A. Bakac, J. Espenson, J. Phys. Chem., 97, 6710, (1993).

12. R. van den Berg, G. Haenen, H. van den Berg, A. Bast, Food Chem., 66, $511,(1999)$.

13. B. Ou, M. Hampsch-Woodill, R. Prior, J. Agric. Food Chem., 49, 4619, (2001).

14. A. M. Campos, E. Lissi, Int. J. Chem. Kinet., 29, 219, (1997).

15. G. Cao, H. M. Alessio, R. Cutler, Free Radic. Biol. Med., 14, 303, (1993).

16. C. López-Alarcón, E. Lissi, Free Radic. Res., 40, 979, (2006).
17. E. Lissi, M. Pizarro, A. Aspée, C. Romay, Free Radic. Biol. Med., 28, 1051, (2000).

18. E. Alarcón, A. M. Campos, A. M. Edwards, E. Lissi, C. López-Alarcón, Food Chem., 107, 1114, (2008).

19. C. López-Alarcón, A. Aspée, E. Lissi, Food Chem., 104, 1430, (2007).

20. E. Pino, E. Lissi, Helv. Chim. Acta., 84, 3677, (2001).

21. K. Reddersen, Th. Heberer, J. Chromatogr. A., 1011, 221, (2003).

22. M. Galmier, B. Bouchon, J. C: Madelmont, F. Mercier, F. Pilotaz, C. Lartigue, J. Pharm. Biomed. Anal., 38, 790, (2005).

23. British Pharmacopoeia 2007, Medicinal and Pharmaceutical substances. 